\title{
Strategic Consideration and Numerical Simulation on Life Extension and Uprating of 25 Years Services Life Coal Fired Generator
}

\author{
Imam Djunaedi, Hilman Syaeful Alam, and Aditya Sukma Nugraha
}

\begin{abstract}
A 471,000kVA Inner-Cooled Turbine Generators, 23kV, .85PF, 3 phases, 50 hertz, $3000 \mathrm{rpm}$ with manufacturing year in 1987, the generator has the service life at over 25 years. The insulation is assumed that is not in an acceptable condition for long term operation and therefore arranges to be performing Life Extension program which will comprise of a full Rewinding of Generator Stator and Generator Rotor. A design margin of the generator should be increased to 494,550 kVA from the current design margin of $471,000 \mathrm{kVA}$, while maintaining the 0.85 power factor. As justification for the Life Extension program, it will require of life assessment. Then a design review of the generator due to increase a design margin needs to be done by determining the performance and life extension of the generator prior to refurbish or uprating. A design review and feasibility study in order to extend the operating life and increase the capability and reability of the generator are performed by using numerical simulation on magnetic analysis, thermal analysis and rotor dynamic analysis. Therefore, the increasing a design margin on the generators from the current design of the margin will not pose a problem as long as all of the following recommendations can be implemented.
\end{abstract}

Index Terms-Generator, insulation, life assessment, life extension, refurbishment, repair, uprating.

\section{INTRODUCTION}

Operated on base load, many generator especially rotor component can provide a trouble-free service life of 25 years or more. However, deregulation in the power industry has forced some generators away from base load operation, and the resulting increased thermal and mechanical cyclic duty has significant consequences for rotating equipment.

In addition, known phenomena such as stress corrosion cracking of retaining rings and torsional resonances, excited by grid transients, have a major impact on rotor design and choice of materials [1]. Generator maintenance options are limited, and they are expensive. Both the timing and the

Manuscript received January 10, 2015; revised October 14, 2015. This research is motivated by a memorandum of understanding (MoU) which has been implemented by the Indonesian Institute of Sciences (LIPI) and PT. Indonesia Power in the fields of research and development of electricity on November 7, 2011 with the MoU Number: 8.MOU/2/IP/2011 and 10/KS/LIPI/IX/2011.

Imam Djunaedi is with the Research Center of Physics, Indonesian Institute of Sciences, Jl. Sangkuriang Komp. LIPI Gd. 80, Bandung, 40135, Indonesia (email: imam003@lipi.go.id; imam_djunaedi@yahoo.com).

Hilman Syaeful Alam is with the Technical Implementation Unit for Instrumentation Development, Indonesian Institute of Sciences, J1. Sangkuriang Komp. LIPI Gd. 30, Bandung, 40135, Indonesia.

Aditya Sukma Nugraha is with the Research Center for Electric Power and Mechatronics, Indonesian Institute of Sciences, J1. Sangkuriang Komp. LIPI Gd. 20, Bandung, 40135, Indonesia. scope of work should be carefully optimized to ensure that maintenance achieves the maximum benefits in terms of cost-effective, trouble-free, long-term operation. The technical decisions regarding what to include and what not to include in a new or refurbished rotor can have significant impact on delivery time and the ability of a new rotor to operate successfully and reliably for the long term, in the new environment [1]-[3]

In addition to the rotor components, the electrical insulation used in stator and rotor windings, as well as core laminations, has a major impact on the reliability of large motors and generators. Failure of the insulation directly or indirectly will result in failure of the machine, which in turn causes forced outages, reduced reliability and increased maintenance and repair costs. Industry surveys have shown that insulation problems are a predominant cause of motor and generator failure. Since many insulation failures originate with aging that occurs over many years, insulation failure rates will increase in older equipment, and thus the electrical insulation will often determine the remaining useful life of a machine. This latter aspect is important in asset management programs to establish current condition [4]. Pressures on utilities to operate more efficiently, and in particular to minimize unnecessary maintenance costs, have created a need to determine the remaining life of components and assessing insulation condition. Consideration must be given to the expected remaining life of the station and the capacity factor requirements over that remaining life. In finding the "right solution" to a repair decision, issues such as repair versus replacement and refurbishment must be considered.

\section{LifE AsSESSMENT METHOD FOR GENERATOR INSULATION}

The cause of the deterioration for the stator coil insulation is mainly the combined one of the electrical, mechanical and thermal one is shown in Fig. 1. The mechanism of the insulation deterioration is caused of electrical, mechanical and thermal stress are accumulated in the insulation, having the interaction each other, due to the increase of the operating hours and the number of starts and stops.

Thus, residual dielectric voltage of the stator coil insulation is reduced in accordance with the increase of the operating hours and the number of starts and stops. Before, when the sampling data from the actual machine is limited, residual life evaluation was done using the data from accelerated deterioration test of the model coils at the laboratory. But today, when the years have passed since the 
synthetic resin had been used, there are lots of machines that have been operated for a long time. So, by sampling the coils from these machines and doing the insulation diagnosis, we can get the more direct residual life evaluation. Taking the stator coil samples from the actual machines and doing the nondestructive electrical test and insulation breakdown test, the evaluation of the residual dielectric voltage had been done. The optimum solution to any serious equipment problem needs to take into account the operating requirements of the plant in question. Consideration must be given to the expected remaining life of the station and the capacity factor requirements over that remaining life. In finding the "right solution" to a repair decision, issues such as repair versus replacement must be considered, along with who is best suited to do the work and where it should be done. Additionally, spare components are a consideration in terms of what types of spares to keep on hand [5], [6].

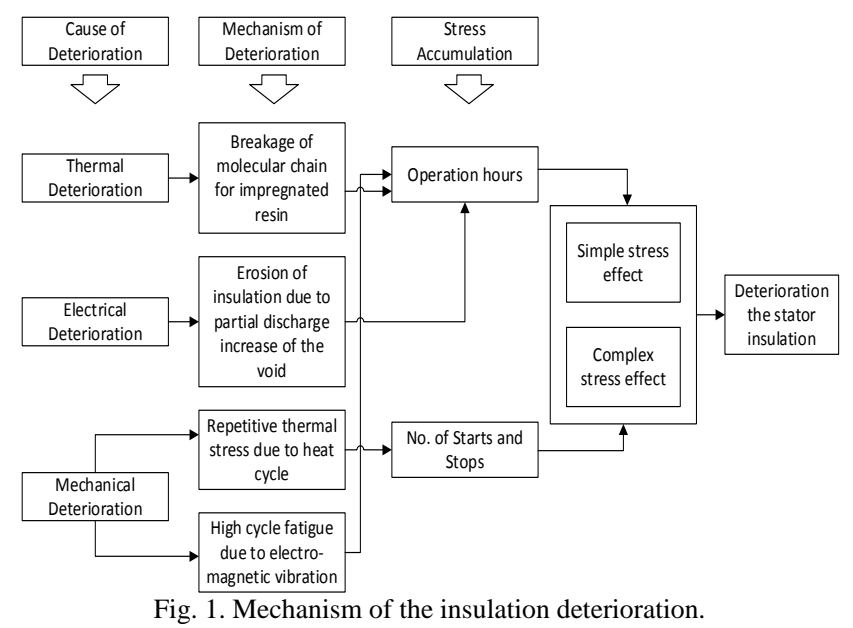

\section{LIFE EXTENSION AND UPRATING CONSIDERATION}

A number of decisions need to be made prior to repair, refurbishment, or rewind work. The fundamental decision to rewind as opposed to replace an old rotor with a new one can be a difficult choice in itself and depends on the individual needs of the utility and the expected future operation of the equipment. The rewind decision will also be based on the known problems as well as possible or potential problems.

It should also be understood that once work commences, there is a possibility that additional items will require attention during the rewind process, as problems are discovered. The main item to consider is the copper winding, and there should be some inspection of the existing copper winding in considering its reuse. This is especially true for a rotor that has already expended its design life and been retired [7].

\section{A. Repair and Replacement Considerations}

For most equipment, including large generator rotors, there are always choices to be made when the component in question is in distress and can no longer function properly. One of the main decisions is whether the component is repairable or should be replaced. This type of choice applies to generator rotors as a whole and for the individual parts that make up the rotor. That is to say, if the rotor cannot operate due to a problem with one if its components, then it may be easy and cost-effective to repair that component or replace it if a spare is available. If the rotor cannot operate due to a number of components being in distress or one of the major components having failed, then it may actually be more technically sound and cost-effective to replace the entire rotor. The point is that many considerations come into play in repair or replacement decisions for rotors. The possibilities may seem limitless at first glance, in light of all the different ways a rotor can fail. However, the two basic choices repair or replacement, regardless of what the failure is. Making that decision for each specific case can be daunting [6].

\section{B. Upgrading / Uprating Rehabilitation}

One of the considerations many utilities today are facing is whether they can get more power out of their existing equipment. In many cases there is already some margin for increased power output inherent in the equipment. However, there is always one component of a generating unit that becomes the limiting piece of equipment when a power uprate is under consideration. In many cases, some equipment may be capable of (for example) a $5 \%$ increase in power output, simply because the margin already exists, but other components of the unit will require some modification or operating change to achieve the $5 \%$. If the $5 \%$ is already available due to the margin, then what happens is the margin gets "used up" in the uprating. If there is no margin and changes are required to achieve the uprate, then it depends on the limiting factor as to what the overall disposition of the piece of equipment in question will be.

In some cases of rotor uprating, the overall generator may be able to handle an increase in the hydrogen pressure inside the machine with no modifications to the casing or hydrogen seals. In this instance, the effect would be to increase the heating in the rotor, but offset it by improved cooling. Therefore, if a utility wanted to increase the power output based on the ability of the generator to handle increased hydrogen pressure, then in theory the net effect should be no change in expected life of the equipment, because there would be no change in temperature.

With regard to the actual uprating of a generator, this always requires calculations to extrapolate operation out to the higher load, based on heat-run testing of the machine at its present maximum load. Once the limitations are known in terms of the limiting components or features of the equipment, some redesign can be considered. It is necessary to determine which components must be replaced, which ones must be modified, what the costs are, and what the time schedule will be to rehabilitate the equipment to the uprated design [6].

\section{DESIGN REVIEW BASEd ON NUMERICAL SiMULATION}

Getting more power out of a generator rotor is to make full use of any margin that exists. The down side of this is that the rotor field current is increased, and the result is a hotter-running rotor winding. The end result is increased temperature and increased mechanical stress on probably all of the rotor components, but primarily on the copper winding and insulations. The effect of increased temperature is a reduction in remaining life of the equipment. 
Conversely, any time a generator upgrade is done to extend life, it is generally prudent to incorporate modifications to increase the available power output, whether a unit uprating is being done or not. This is simply good business sense and future planning. The cost of carrying out some uprating modifications is usually negligible when a full rewind is already being performed.

One other way of getting more power out of a generator, while making no changes to the equipment itself or to the cooling, is to restrict the power factor of generator more towards unity. This is essentially just rerating the machine and curtailing its lagging power factor capability. However, this is not a generally accepted method of achieving more power output because of the system needs for reactive power.

\section{A. Magnetic Evaluation Method}

Analysis of the magnetic field in an electrical machine can be done analytically and numerically. Numerical method hould have more accurate calculation than analytical method when the disrete elements more fine eventhough more take time [7], [8]. Analysis of magnetic field needs to be done to prevent saturation of the magnetic field in the core laminate which can lead to the emergence of heat concentration [9]. Laminate material that most widely used in the rotating electric machinee is a silicon steel [10]. The silicon content in the steel can increase the resistivity volume to decrease the flow eddy and reduce a hysteresis. The amount of the silicon content in the silicon steel ranged between $0.5 \%$ $3.25 \%$ [11]. In general, the magnetic characteristics of the core lamination is shown in the magnetic saturation region present in the area $1.7-2 \mathrm{~T}$, therefore the flux that flows must be maintained and not to reach the saturation point. If this value is exceeded then the magnetization current will deviate from the sinusoidal shape and contains harmonics [12].

The distribution of magnetic flux is simulated using FEMM 4.2 software which bases its calculations using Maxwell's equations. The general steps of simulation are shown in Fig. 2. Each step shown an input parameter that must be met before the execution of the simulation is done.

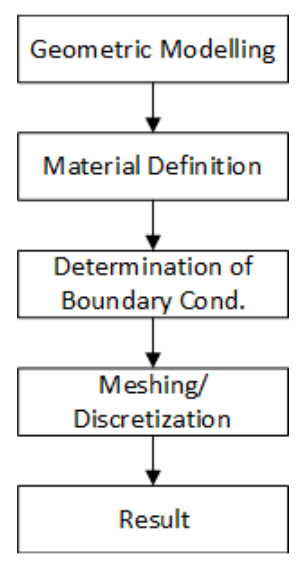

Fig. 2. The main steps of magnetic field simulation using FEMM 4.2.

In the meshing phase, the observed object is divided into small triangular elements. Simulation execution speed is strongly influenced by the specifications of the computer being used. In this study, the simulation time is quite fast because of the object being observed only in two-dimensional form.

In this study the magnetic field analysis performed numerically using FEMM 4.2 software. Flux density is analyzed on the stator teeth and the air gap which is the critical places of the flux concentration, flux distribution patterns and flux fluctuations in the generator and its influence on the generation of electromotive force (EMF) in nominal load.

For the simulation results using finite element, flux distribution on the stator region for $7 \%$ uprating (Fig. 3) are below $1.0 \mathrm{~T}$.

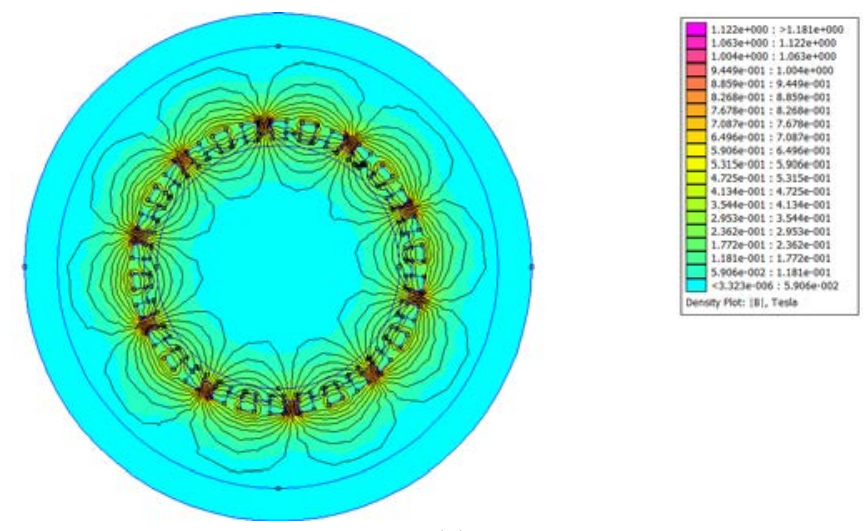

(a)

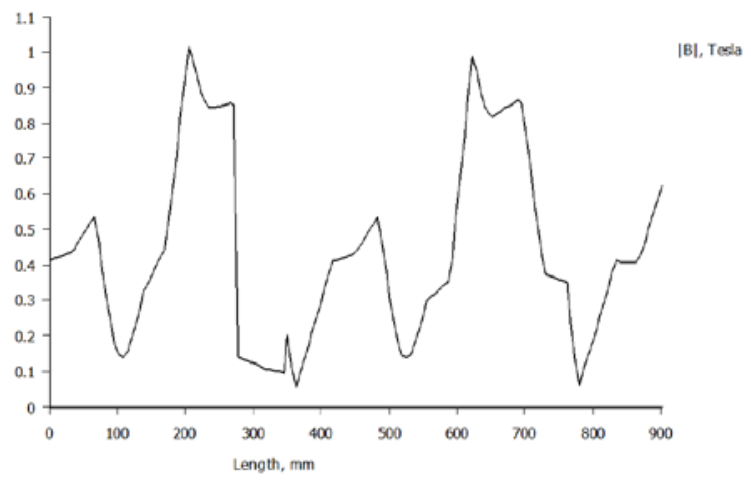

(b)

Fig.3 (a) Distribution of flux density at stator in 7\% uprating, (b) Flux distribution at stator

\section{A. Thermal Evaluation Method}

One of the considerations in many power plants is how they get more power out of their existing equipment. In many cases, some equipment may be capable of a $5 \%$ increase in power output or uprating, because the margin already exists [13]. For generators, one way to uprating is to the make full use of any margin that exists to raise the field current and thereby increase the power output, but the consequences will raise the temperature and stress on probably all of the generator components, and primarily on the copper winding and insulations. Whereas according to the Azizi et al. [14], the troubles initiated in the insulation are one of the primary root causes of failures of electric machines because one-third of the forced outages of large generators in generating stations and industrial plants are the caused by the failure of insulation systems. In some cases, most of generators may be able to handle the increasing temperature by modifying the cooling system. For large generator with a cooling system using hydrogen, the modification can be done by increasing the hydrogen 
pressure inside the machine, but the method is limited by the strength of other components for example casings or hydrogen seals. Therefore, thermal analysis is needed to determine the effect on the increasing of hydrogen pressure in the cooling system. In addition, temperature distribution analysis is highly necessary to ensure there is no heat concentration point or hotspot that might cause damage to the insulation on the winding or demagnetization.

Since the ability and speed of modern computers has increased rapidly and allows to run the calculations in a relatively short time, the thermal analysis of electric machines has become an interesting research field for both industry and investigators to improve the cooling performance and to enhance the efficiency of electric machine. In order to predict precisely the thermal characteristics of electric machines, thermal analysis can be divided into two methods: Lumped Parameter Thermal Model (LPTM) and numerical method. The LPTM is the main tool for a fast yet accurate thermal analysis. However, a common drawback to this approach can make it useless to a designer, because there is a need for experimental data in order to tune parameters that are very important in order to obtain accurate results [15]. It is of common practice in thermal modeling of electric machine to use the lumped thermal method, however if higher level of details is required, it needs to use the more refined methods like numerical method based on finite element or finite difference. These types of methods can give a highly accurate and clear view of the temperature distribution within the electric machine [16], [17].

This paper considers the thermal analysis on a $400 \mathrm{MW}$ hydrogen cooled generator using numerical method based on finite element. Thermal analysis is focused to determine its influence on the increasing of hydrogen pressure in the generator cooling system. In addition, the temperature distribution on the generator was studied to ensure there is no heat concentration point or hotspot that might cause damage to the insulation or demagnetization.

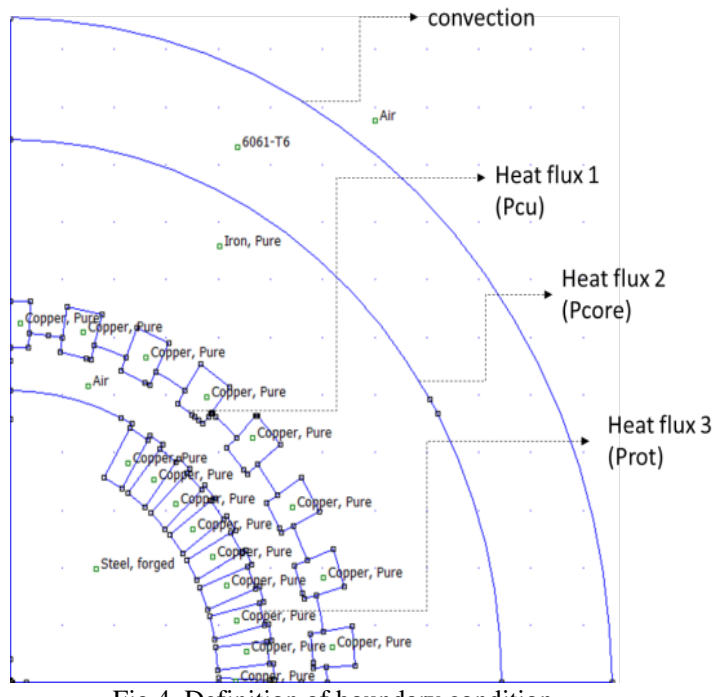

Fig.4. Definition of boundary condition.

Geometry of the generator is shaped into a quarter of segment or one quadrant of the $2 \mathrm{D}$-generator. This is because of the other parts of segments are symmetrical.

Thermal simulation process by FEMM 4.2 using two boundary conditions, the first is the heat flux as a source of heat generated from the calculation of losses in the generator ( $\mathrm{P}_{\text {rot }}, \mathrm{P}_{\text {cu }}$ and $\mathrm{P}_{\text {core }}$ ) the second is the convection boundary conditions are applied to the area or boundaries related to the ambient temperature. The boundary conditions are shown in Fig. 4 and marked with dashed arrow lines.

For $7 \%$ Uprating with Force Air Convection the temperature distribution represented in a 2-dimensions form for each generator segment with natural convection is displayed in Fig.5. From the figure it can be seen that no heat concentration or hotspot exists. Every generator segment receives relatively the same temperature flow (evenly). As the whole, temperature variation takes place within the range of $3.082 \cdot 10^{2} \mathrm{~K}-4.694 \cdot 10^{2} \mathrm{~K}$.

The highest temperature exists at winding area as the area holds the biggest heat flux of $4.694 \cdot 10^{2} \mathrm{~K}$ or $196.4{ }^{0} \mathrm{C}$. Meanwhile the lowest temperature is found at the area of rotor shaft because this area contains convectional heat transfer mechanism at two areas, i.e. rotor and air gap.
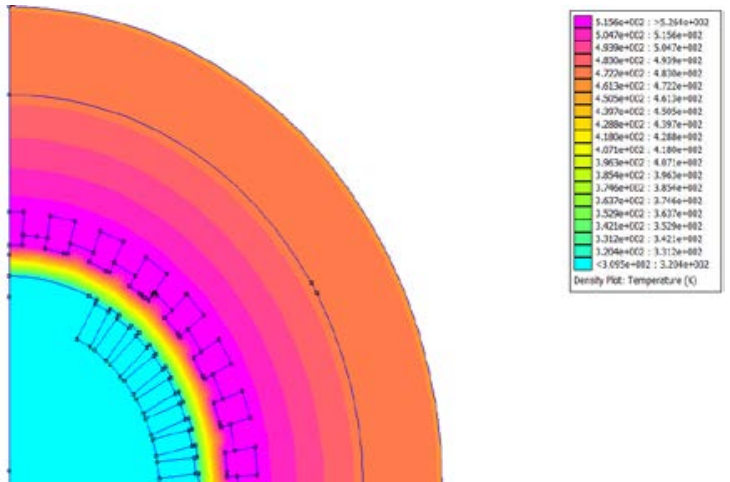

Fig. 5. Temperature distribution for 7\% Uprating with force air convection.

\section{B. Rotor-Dynamic Evaluation}

The problems in designing the rotating machinery including generator is the vibration, because the vibration is usually a direct cause of the component damage. Every spinning rotor has some vibration, at least a once-per-revolution frequency component (1st order) therefore it is impossible to make any rotor perfectly mass balanced. Rotor-dynamic analysis is essential for quantifying safe upper limits of allowable vibration levels by analyzing the critical speed of the system which is very useful. It can provide information about the resonance region of the system and can be used as a standard to monitor the possibility of harmful, due to damage of the components. In addition, it is very useful for designers in understanding the relationship between the selection of design schemes including the shaft size, bearing properties, housing stiffness and machine stability [18].

There are two methods which are often adopted to deal with rotor dynamic problem. One is the transfer matrix method, such as Riccati transfer matrix method and the other is the finite element method (FEM), which has higher numerical stability but need more storage space of the computer. Both methods are widely used to solve the rotor dynamic problem. The former method divides the system into several parts after it gets the lumped mass model, such as the disk, the shaft and the bearing. Then it establishes the relation of the state vectors between the both ends of the cross-section and use the continuity conditions to obtain the 
relation between the state vectors in any cross section and the initial one. The latter method, namely FEM, was not adopted to analyze rotor dynamic problem until 1970s. The key idea of the FEM is to transform the infinite DOF (Degrees Of Freedom) problem into a finite number of DOF, and then solve it. As the computer technology develops, the FEM become very popular to analyze mechanical problems, not just the rotor dynamic [19].

The FEM has several advantages such as reduction of time when solving complex equation system. In addition, it can be applied by the software and can be widely applied in solving problems in engineering field for high accuracy and flexibility [20]. By looking at the complexity of the structure that will be analyzed, it is necessary to do simulations using finite element method. The idea of this method is to divide the elements relevant to the complex structure into many elements, where the elements - these elements are part of a continuous structure. With this calculation method global matrix which is the unity of the part of many of these elements can be easily assembled and computed.

From the simulation results of the rotor dynamics at $100 \%$ operating speed, the rotational speed of $3000 \mathrm{rpm}$ is obtained a critical rotation speed of the rotor at 1500 and 1800 rpm that are shown in Fig. 6. Modes shape when a critical rotation occurs can be seen in Fig. 7. The function of rotor shape in times of critical rotation is characteristic of the rotor will experience a bending mode due to rotation of the rotor [21].

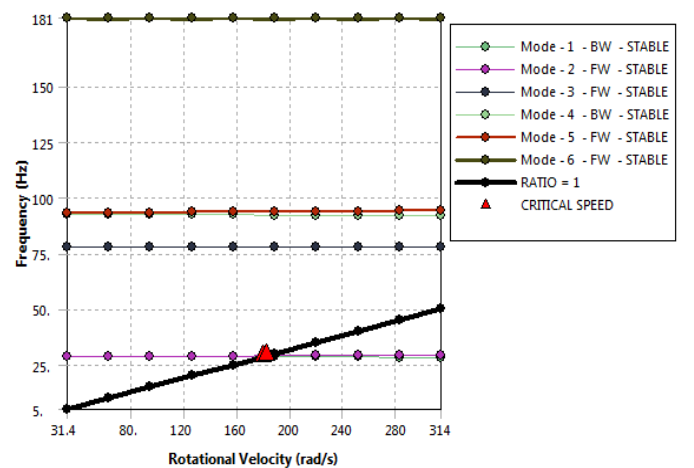

Fig. 6. Campbell diagram at $3000 \mathrm{rpm}$.

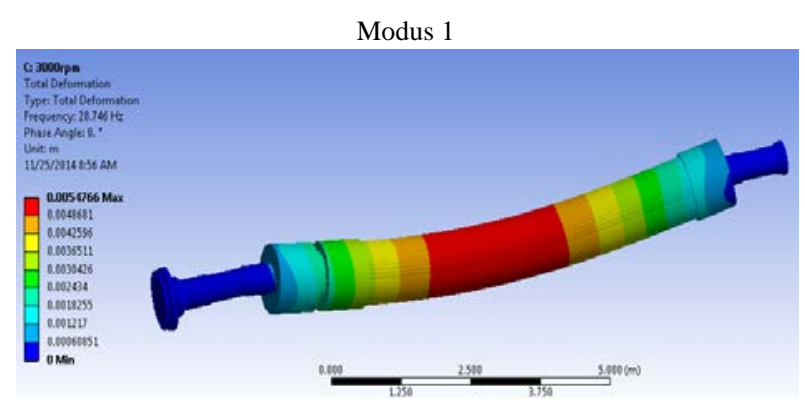

Modus 2

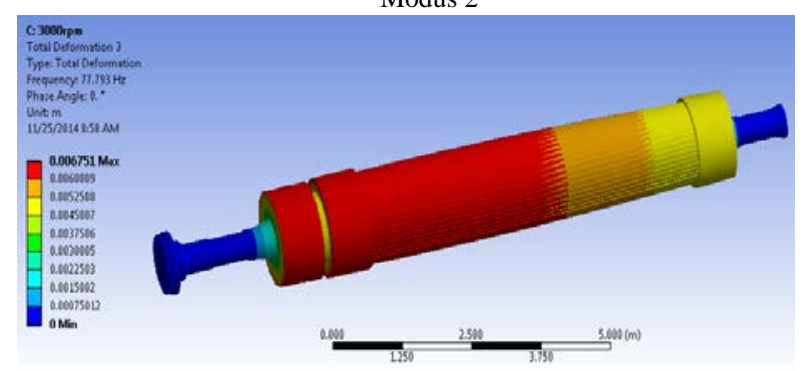

Modus 3

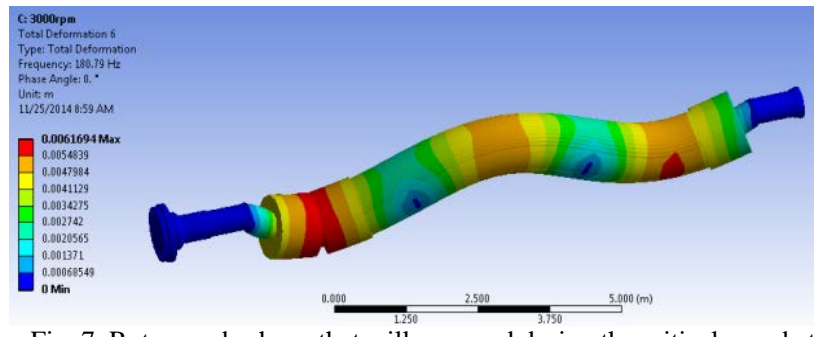

Fig. 7. Rotor mode shape that will occurred during the critical speed at $3000 \mathrm{rpm}$.

\section{CONCLUSION}

The remaining life assessment of generator insulation is calculated based on the stress combination of electrical, mechanical and thermal factors which are accumulated by the operating history such as number of start-stop times and operating hours. The lifetime of insulation was evaluated at worst case and average case. A design review and feasibility study in order to extend the operating life and increase the capability and rehabilitee of the generator are performed using magnetic analysis, thermal analysis and rotor dynamic analysis. Therefore, the increasing a design margin on the generators from the current design of the margin of 471,000 $\mathrm{kVA}$ to $494,550 \mathrm{kVA}$ with the 0.85 power factor will not pose a problem as long as all of the considerations can be implemented.

\section{REFERENCES}

[1] EPRI, “Optimized maintenance of generator rotors," 2004.

[2] EPRI, "Guidelines for reducing the time and cost of turbine-generator maintenance overhauls and inspections," Turbine-Generator Component Procurement Specifications, vol. 4, 2007.

[3] EPRI, "Guidelines for reducing the time and cost of turbine-generator maintenance overhauls and inspections," General Practices, vol. 1, 2007.

[4] EPRI, "Guide for electric motor stator winding insulation design, testing and VPI resin treatment," 2004.

[5] EPRI, "Life Assessment Methodology for Turbo generator Rotor," vol. 1, 1988 .

[6] EPRI, "Motor and generator insulation life estimation," vol. 1, 2 \& 3, 1992.

[7] EPRI, "Guide for rewinding and reconditioning medium voltage electric motor," 1996.

[8] D. Žarko, T. A. Lipo, D. Ban, "Analytical calculation of magnetic field distribution in the slotted air gap of a surface pm motor using complex relative air gap permeance," IEEE Transaction on Magnetics, vol. 42, no. 7, pp. 1828-1837, July 2006.

[9] G. Mahalingam and A. Keyhani, "Design of 42v/3000w permanent magnet synchronous generator," Technical Report, Electrical Engineering Department, Ohio State University, Columbus Ohio, 2000 .

[10] E. S. Hamdi, Design of Small Electrical Machine, D.V. Morgan, Ed England: John Wiley \& Sons, 1994.

[11] A. Parviainen, "Design of axial-flux permanent-magnet low-speed machines and performance comparison between radial-flux and axial-flux machines," Ph.D. Thesis, Lappeenranta University of Technology, Finland, 2005.

[12] R. H. Staunton et al., "PM motor parametric design analyses for a hybrid electric traction drive application," Working paper, Oak Ridge National Laboratory, Department of Energy, Tennessee, Laporan Penelitian, 2004.

[13] K. Fujisaki, R. Hirayama, and Y. Nemoto, "Electromagnetic steel solution in electromagnetic field," Technical Report, Environment \& Process Technology Center, Technical Development Bureau, Nippon Steel Corporation, Electrical Steel Sheet, 2004.

[14] D. Azizi, A. Gholami, "Optimization of semiconductive coating and ground wall insulation layers in stator slot of HV generator," Electrical Power and Energy Systems, no. 57, pp. 384-391, 2014.

[15] P. Irasari, H. Syaeful Alam, and M. Kasim, "Thermal analysis on radial flux permanent magnet generator $(\mathrm{PMG})$ using finite element 
method,” The Journal for Technology and Science, vol. 22, no. 2, May 2011.

[16] J. A. Malumbres, M. Satrustegui, I. Elosegui, J. C. Ramos, and M. Martínez-Iturralde, "Analysis of relevant aspects of thermal and hydraulic modeling of electric machines. Application in an open self-ventilated machine,” Applied Thermal Engineering, no. 75, pp. 277-288, 2015

[17] Z. Zhanga, S. M. Muyeenb, A. Al-Durrab, R. Nilssena, and A. Nysveena, "Multiphysics 3D modeling of ironless permanent magnet generators," Energy Procedia, vol. 53, pp.34-43, 2014.

[18] F. Trebuňa1, P. Frankovský, M. Gulaa, and P. Hudák, "Numerically computed dynamics rotor using ansys software," in Proc. the 4th International Conference: Modelling of Mechanical and Mechatronic systems, Herl'any, Slovak Republic, 2011, pp. 498-501.

[19] B. Bai, L. Zhang, T. Guo, and C. Liu, "Analysis of dynamic characteristics of the main shaft system in a hydro-turbine based on ANSYS,” Procedia Engineering, vol. 31, pp. 654-658, 2012.

[20] H. Taplak and M. Parlak, "Evaluation of gas turbine rotor dynamic analysis using the finite element method, Measurement," vol. 45, pp. 1089-1097, 2012.

[21] Indonesian Institute of Sciences, "Life extension and generator uprating of coal fired power plant unit 3-4 for PT. Indonesia power," technical report, December 2014.

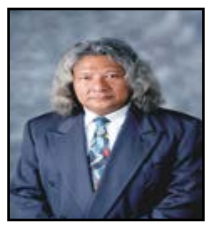

Imam Djunaedi received his B.S. degree in mechanical engineering from Institut Technology Bandung, Indonesia in 1984. He had been research as a Ph.D. research student at School of Computer \& Electrical Engineering Curtin University of Technology, Australia from 1993 to 1996. He worked as a researcher at Indonesian Institute of Sciences (LIPI) from 1986 until now. His research areas are renewable energy, optimization, mechatronics, thermal engineering and power plant.

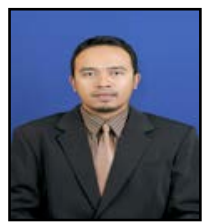

Hilman Syaeful Alam received his B.S. degree in mechanical engineering from Jenderal Achmad Yani University, Indonesia in 2003 and M.S. degree in mechanical engineering from Institut Teknologi Bandung, Indonesia in 2010, He worked as a researcher at Indonesian Institute of Sciences (LIPI) from 2006 until now. His research areas are power generation, renewable energy, energy conversion, engineering design, intelligent material \& structures, instrumentation \& control, finite element and computational mechanics.

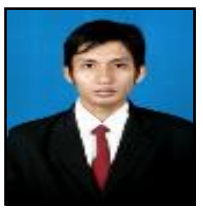

Adit Sukma Nugraha received his B.S. degree in mechanical engineering from Diponegoro University, Indonesia in 2006 and M.S. degree degree in mechanical engineering from Institut Technology Bandung, Indonesia in 2014; He worked as a researcher at Indonesian Institute of Sciences (LIPI) from 2008 until now. His research areas are mechatronics, vibration, and renewable energy. 